\title{
Growth Technology and Optical Properties of Bulk Crystalline Gallium Oxide
}

\author{
D.I. Panov', V.A.Spiridonov' ${ }^{1}$ D.A. Zakgeim ${ }^{1,2}$,A.V. Kremleva1, D.A. Bauman', \\ A.E. Romanov ${ }^{1,2}$ and V.E. Bougrov ${ }^{1}$
}

'ITMO University, Kronverkskiy pr. 49, St. Petersburg, 197101, Russia

${ }^{2}$ Ioffe Institute, Polytechnicheskaya 26, St. Petersburg, 195251, Russia

Received: July 15, 2020

\begin{abstract}
In this paper we report on the bulk $\beta-\mathrm{Ga}_{2} \mathrm{O}_{3}$ crystals growth from the melt. Czochralski technique with different configurations of the growth zone was used. It has been shown that the magnitude of the vertical temperature gradient near the melt/crystal interface is crucial for the stability of the growth process and the quality of the growing crystal. In addition, it is necessary to add oxygen to the atmosphere of the growth chamber for stable crystal growth. The optical properties of the grown $\beta-\mathrm{Ga}_{2} \mathrm{O}_{3}$ crystals were investigated.
\end{abstract}

\section{INTRODUCTION}

Currently, numerous research groups are developing new semiconductor materials. One of such promising materials is beta-gallium oxide $\left(\beta-\mathrm{Ga}_{2} \mathrm{O}_{3}\right) \cdot \beta-\mathrm{Ga}_{2} \mathrm{O}_{3}$ monocrystal is a wide-gap semiconductor with a band gap $\sim 4.8 \mathrm{eV}$, high breakdown electric field ( $>8 \mathrm{MV} / \mathrm{cm})$, and relatively high electron mobility $\left(\sim 150 \mathrm{~cm}^{2} / \mathrm{Vs}\right)$ [1-4]. The first references to the successful fabrication of gallium oxide devices with record-breaking characteristics began to appear in the literature. For example, in [5] the authors report the creation of a MOSFET with a breakdown voltage above $1000 \mathrm{~V}$.

Pure $\beta-\mathrm{Ga}_{2} \mathrm{O}_{3}$ is transparent in visible and UV parts of electromagnetic spectrum $[3,6]$; that opens up the possibility of fabricating transparent conductive substrates from this material for the epitaxy of optoelectronic structures based on III-nitrides [7].

From a technological point of view, gallium oxide looks preferable to other wide band gap materials, such as $\mathrm{GaN}, \mathrm{AlN}$, and $\mathrm{SiC}$ due to the fact that it can be relatively easily fabricated in the form of a bulk crystal. The most common method for $\beta-\mathrm{Ga}_{2} \mathrm{O}_{3}$ production is the growth from the melt in two main modifications:
Czochralski(CZ) technique $[6,8]$ and Edge defined Filmfed Growth (EFG) $[9,10]$.

However, the growth of bulk crystals of gallium oxide from the melt is complicated by the tendency of this material to chemical decomposition at the melting temperature. Depending on the external redox conditions, the $\mathrm{Ga}_{2} \mathrm{O}_{3}$ melt can decompose into divalent gallium oxide, monovalent oxide and, finally, metallic gallium $\left(\mathrm{Ga}_{2} \mathrm{O}_{3} \rightarrow \mathrm{GaO} \rightarrow \mathrm{Ga}_{2} \mathrm{O} \rightarrow \mathrm{Ga}\right.$ and $\left.\mathrm{O}_{2}\right)$. Metallic gallium, in turn, is able to form intermetallic alloys with elements of growth equipment, including crucibles from precious metals (for example Ir-Ga), which, ultimately, renders them unusable. On the other hand, violation in the stoichiometry of the melt leads to the formation of defects in the growing crystals. A lot of recent papers are devoted to studies of the growth atmosphere influence on the crystalline perfection and physical properties of the grown $\beta-\mathrm{Ga}_{2} \mathrm{O}_{3}$ crystals $[11,12]$. Galazka's group published a series of papers on the use of an oxygen-containing atmosphere when growing gallium oxide crystals by Czochralski technique $[3,6,12,13]$.

In this paper we investigated the possibility of obtaining high quality single-crystals of $\beta-\mathrm{Ga}_{2} \mathrm{O}_{3}$ by $\mathrm{CZ}$

Corresponding author: D.I. Panov, email: dmitriipnv@itmo.ru 

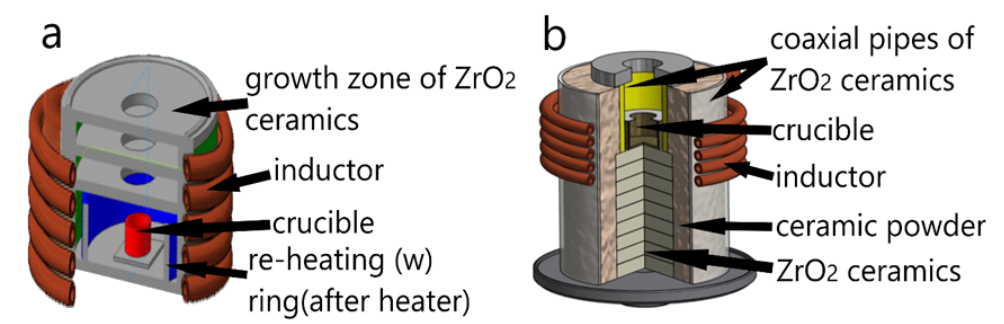

Fig. 1. Schematics of the growth zone used for Czochralski growth of $\beta-\mathrm{Ga}_{2} \mathrm{O}_{3}$ from the melt. a) The zone with re-emitting ring; b) The zone with direct heating of crucible.

method in inductively heated growth zone. The configuration of reactor growth zone was optimized carefully in order to provide optimal temperature distribution in the vicinity of melt/crystal interface. The possibility of using of a relatively massive tungsten ring as re-emitting "after heater" was evaluated. The growth atmosphere was varied from pure argon to the mixture of argon and carbon dioxide as a source of oxygen near the melt surface. The optical properties of grown crystals, such as transmittance spectra, were analyzed.

\section{EXPERIMENTAL}

Growth processes were carried out in the industrial growth system "Nika-3" having an inductively heated growth zone. Powdered $99.99 \%$ (4N) $\mathrm{Ga}_{2} \mathrm{O}_{3}$ was used as a source material. Iridium (Ir) crucible with a diameter of $40 \mathrm{~mm}$ and a height of $25 \mathrm{~mm}$ was used to produce the melt, and a crystalline sapphire $\left(\mathrm{Al}_{2} \mathrm{O}_{3}\right)$ was used as the seed. In some experiments, a tungsten ring was used as a re-emitting concentrator ("after heater"). The growth chamber was evacuated to the residual pressure of $10^{-2}$ mbar before each process, after which it was filled with a mixture of gases, argon (Ar) and carbon dioxide $\left(\mathrm{CO}_{2}\right)$ in various ratios. The operating pressure in the chamber was 1.5 Bar.

Two series of experiments with different configurations of growth zones were carried out:

1) In the first series of experiments, a set of $\mathrm{ZrO}_{2}$ disks with a diameter larger than the diameter of the crucible was used as the growth zone thermal insulation. The growth was carried out in the pure Ar atmosphere at a pressure of 1.5 Bar. A massive tungsten ring with a diameter of $95 \mathrm{~mm}$ and a height of $65 \mathrm{~mm}$ was used as an induction radiation re-emitter, screening the Ir crucible from the RF radiation of inductor. Schematics of the growth zone with a re-emitting ring is shown in Fig. 1a. 2) In the second series of experiments, the re-emitting ring was removed from the growth zone and the Ir crucible was directly heated by induction currents. Coaxial pipes made of $\mathrm{ZrO}_{2}$ ceramics were used as a growth zone thermal insulation, the space between them was filled with a ceramic powder. Schematics of this zone is shown in Fig.1b. The growth atmosphere was a mixture of $\mathrm{Ar}$ and $\mathrm{CO}_{2}$ in various ratios (including pure $\mathrm{CO}_{2}$ ), with a total pressure of 1.5 Bar.

\section{RESULTS AND DISCUSSION}

\subsection{Growth processes}

In the first series of experiments, the following issues were addressed by introducing a re-emitting tungsten ring. The first issue was the protection of the Ir crucible by screening it from RF power of inductor. If micro-cracks exist in the crucible, induced currents and corona discharges can occur at them, leading to local overheating and even local melting of the crucible. The second issue was the providing of an optimal (smooth) vertical temperature gradient in the growth zone due to the large height of the re-emitting ring. While the growing crystal is pulled out of the melt, it should not be subjected to an abrupt cooling, leading to the emergence of thermal stresses. Relaxation of the resulting stresses provokes the formation of extended structural defects and cracking of the growing crystal.

A serious downside of using a massive tungsten reemitter is a significant increase in the inertia of the temperature response of the system to the changes in the power supplied to the inductor. This makes it very difficult to control the growth process by the weight sensor and, as a result, it turns out to be impossible to achieve stabilization of the growing crystal shape. During the growth process, the uncontrolled expansion of the crystal in lateral direction occurred followed by its melting when approaching crucible walls. This resulted in spiral shape of grown crystals(see Fig. 2a). In addition, the utilization of a tungsten ring in the growth zone imposes a restriction on the composition of the growth atmosphere - only inert Ar atmosphere could be used, since the presence of even a small oxygen concentration leads to intensive oxidation of tungsten at the temperatures required for $\mathrm{Ga}_{2} \mathrm{O}_{3}$ melting. However, it is also known that the growth of the high quality $\beta-\mathrm{Ga}_{2} \mathrm{O}_{3}$ requires the usage of oxygen-containing atmospheres [13]. In an inert growth atmosphere, the gallium oxide melt decomposes into volatile components and metallic $\mathrm{Ga}$ 

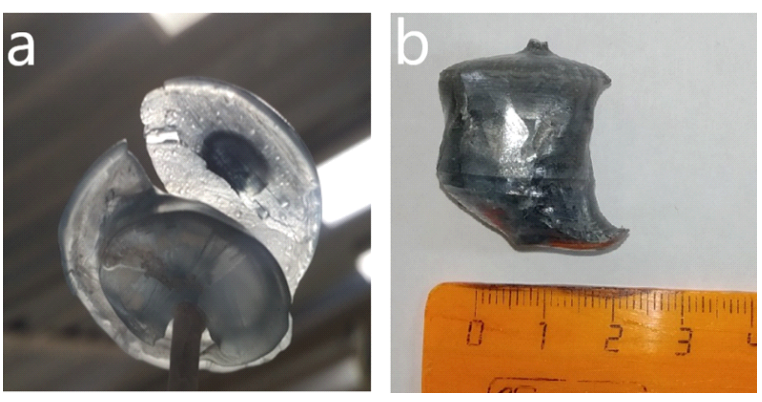

Fig. 2. Examples of Czochralski grown $\beta-\mathrm{Ga}_{2} \mathrm{O}_{3}$ crystals.

$\left(\mathrm{Ga}_{2} \mathrm{O}_{3} \rightarrow \mathrm{GaO} \rightarrow \mathrm{Ga}_{2} \mathrm{O} \rightarrow \mathrm{Ga}\right.$ and $\left.\mathrm{O}_{2}\right)$ [14]. The appearance of free gallium leads to the formation of an intermetallic compound Ir-Ga, which, in turn, results in the destruction of the crucible [15]. Intensive formation of volatile compounds leads to the deposition of amorphous gallium oxide on the walls and other parts of the chamber, and even on the surface of the growing crystal (one can see the white coating on the crystal shown in Fig. 2a). Moreover, the melt stoichiometry violation results in degradation of growing crystal quality.

Therefore, we also used growth zone with direct heating of Ir crucible by RF power of inductor without intermediate tungsten re-emitter. This allowed us to introduce oxygen into the growth atmosphere in order to chemically stabilize $\mathrm{Ga}_{2} \mathrm{O}_{3}$ melt, $\mathrm{CO}_{2}$ was used as a source of oxygen. At the gallium oxide melting temperature (about $1850^{\circ} \mathrm{C}$ ), it partially decomposes into $\mathrm{CO}$ and $\mathrm{O}_{2}$ emitting up to 1 vol.\% of molecular oxygen $[16,17]$. The presence of oxygen significantly reduced the rate of melt decomposition, resulting in much cleaner crystal surface.

The removal of a massive tungsten ring from the growth zone resulted in substantial acceleration of the melt temperature response to the changes in the power supplied to the inductor. We were able to control the shape of growing crystal by weight sensor. However, in
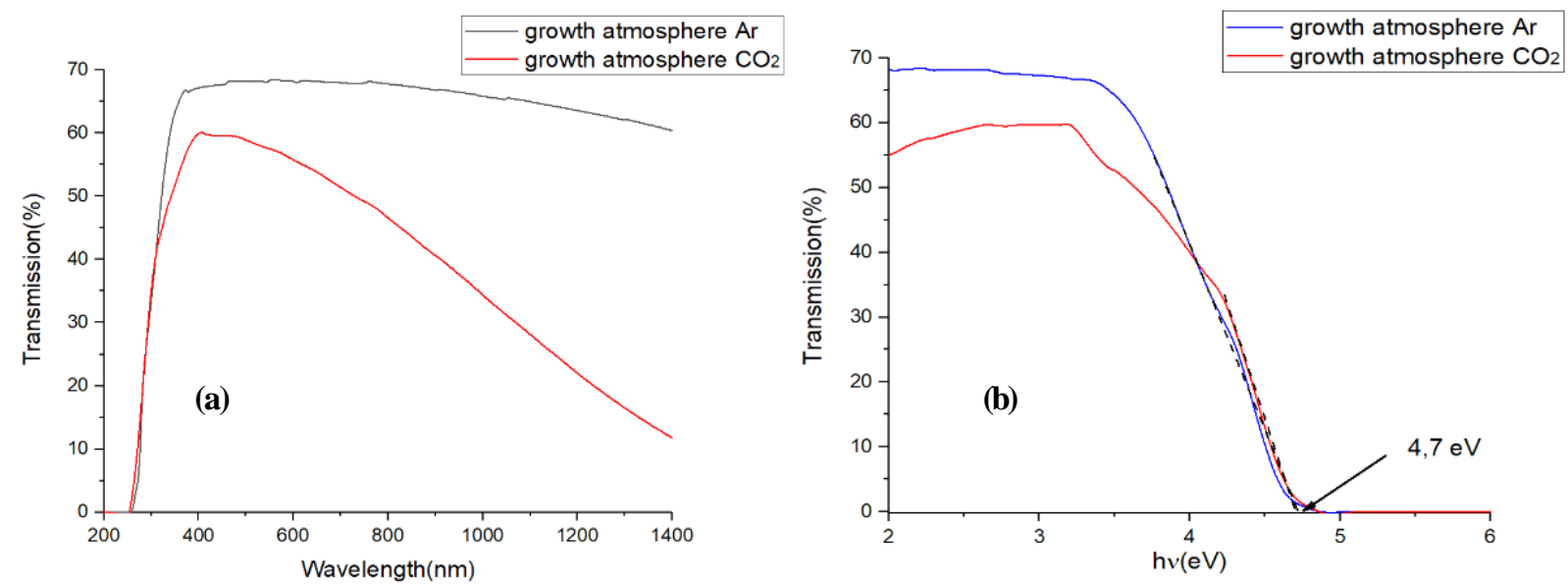

Fig. 3. Spectra of optical transmission of grown $\beta-\mathrm{Ga}_{2} \mathrm{O}_{3}$ crystals as a function of wavelength (a) and photon energy (b). the absence of massive heat source we had to significantly upgrade the growth zone thermal insulation in order to decrease temperature gradient in the vicinity of the melt/crystal interface. As a thermal insulation, coaxial pipes made of zirconium ceramics were used, the space between them was filled with ceramic powder. This configuration of thermal insulation significantly suppressed gas convection near the crucible and greatly reduced heat loss. As a result, we were able to achieve the desired vertical temperature gradient and to accurately monitor the growth rate,weight, and diameter of the growing crystal. As can be seen from Fig. 2b, the cylindrically shaped $\beta-\mathrm{Ga}_{2} \mathrm{O}_{3}$ boules were reproducibly grown.

\subsection{Optical properties}

The optical properties of the obtained $\beta-\mathrm{Ga}_{2} \mathrm{O}_{3}$ crystals were studied. The optical transmission spectrum was measured on a plane-parallel plates with a thickness of 1 mm using "Photon RT" system. Plates were made by cleaving the crystal along the crystallization interface, which allowed to have smooth enough samples without any additional surface treatment.

Since the melt of $\mathrm{Ga}_{2} \mathrm{O}_{3}$ is chemically unstable, the growth atmosphere composition affects significantly the electrical and optical properties of the grown crystal. From transmission spectra shown in Fig. 3a, one can see that in the IR spectral region the absorption of the sample grown in oxygen-containing atmosphere is much higher than that of the sample grown in pure Ar. The melt stoichiometry violation results in formation of defects in the crystal, which reduce the concentration of free electrons responsible for IR absorption. This observation was supported by the data from the work [6], where authors studied the influence of growth atmosphere composition on the concentration of free electrons in the resulting crystal. 
The analysis of the $\beta-\mathrm{Ga}_{2} \mathrm{O}_{3}$ crystal optical absorption edge (Fig. 3b) allows to estimate optical band gap of the grown wide bandgap material to be approximately $4.7 \mathrm{eV}$. This value is slightly smaller than data reported by other research groups $[6,12,14]$, probably, due to the presence of high concentration of defects in our crystals.

\section{CONCLUSIONS}

In this work, we have studied the process of growing of $\beta-\mathrm{Ga}_{2} \mathrm{O}_{3}$ crystals by the Czochralski technique using various configurations of growth zone and different compositions of growth chamber atmosphere. It has been shown experimentally that oxygen-containing atmosphere is required for stable growth of high-quality crystals. This imposes serious limitations on materials, from which hot elements of growth zone are fabricated. Only iridium, which is stable in oxygen-containing atmosphere at $\mathrm{Ga}_{2} \mathrm{O}_{3}$ melting temperature, can be recommended to use as crucible and/or other RF power concentrators. In case of direct heating of crucible by RF radiation of inductor, the thermal insulation of growth zone should be carefully adjusted in order to provide required temperature distribution in vertical direction near the melt surface. By doing this we have succeeded in fabrication of cylindrically shaped $\beta-\mathrm{Ga}_{2} \mathrm{O}_{3}$ boules having about $2 \mathrm{~cm}$ in diameter. The reasonable crystal quality of obtained bouleshas been proved by optical transmittance measurements. The band gap about 4.7 $\mathrm{eV}$ has been estimated from absorption edge.

\section{ACKNOWLEDGEMENTS}

This work was supported by the Russian Science Foundation, Project No. 19-19-00686.

\section{REFERENCES}

[1] S. J. Pearton, J. Yang, P. H. Cary, F. Ren, J. Kim, M. J. Tadjer and M. A. Mastro, A review of $\mathrm{Ga}_{2} \mathrm{O}_{3}$ materials, processing, and devices, Appl. Phys. Rev., 2018, vol. 5, art. 011301. https://doi.org/ $10.1063 / 1.5006941$

[2] S. I. Stepanov, V.I. Nikolaev, V. E. Bougrov and A.E. Romanov, Gallium Oxide: Properties and Applications - a Review, Rev.Adv.Mater.Sci., 2016, vol. 44, no. 1, pp. 63-86. http://www.ipme.ru/ejournals/RAMS/no_14416/06_14416_stepanov.pdf

[3] Z. Galazka, $\beta$ - $G a_{2} \mathrm{O}_{3}$ for wide-bandgap electronics and optoelectronics, Semicond. Sci. Technol., 2018, vol. 33, no. 11, art. 113001. http://dx.doi.org/ 10.1088/1361-6641/aadf78

[4] E. Chikoidze, A. Fellous, A. Perez-Tomas, G. Sauthier, T. Tchelidze, C. Ton-That, T.T. Huynh,
M. Phillips, S. Russell, M.R. Jennings, B. Berini, F. Jomard and Y. Dumont, P-type $\beta$-gallium oxide : a new perspective for power and optoelectronic devices, Mater. Today Phys., 2017, vol. 3, pp. 118-126. https://doi.org/10.1016/ j.mtphys.2017.10.002

[5] Z. Hu, K. Nomoto, W. Li, N. Tanen, K. Sasaki, A. Kuramata, T. Nakamura, T. Jena and H. G. Xing, Enhancement-mode $\mathrm{Ga}_{2} \mathrm{O}_{3}$ vertical transistors with breakdown voltage $>1 \mathrm{kV}$, IEEE Electron Device Lett., 2018, vol. 39, no. 6, 869-872. https://doi.org/10.1109/LED.2018.2830184

[6] Z. Galazka, K. Irmscher, R. Uecker, R. Bertram, M. Pietsch, A. Kwasniewski, M. Naumann, T. Schulz, R. Schewski, D. Klimm and M. Bickermann, On the bulk $\mathrm{\beta}-\mathrm{Ga}_{2} \mathrm{O}_{3}$ single crystals grown by the Czochralski method, J. Cryst. Growth, 2014, vol. 404, pp. 184-191. https://doi.org/10.1016/j.jcrysgro.2014.07.021

[7] T. Minami, T. Shirai, T. Nakatani and T. Miyata, Electroluminescent Devices with $\mathrm{Ga}_{2} \mathrm{O}_{3}: \mathrm{Mn}$ ThinFilm Emitting Layer Prepared by Sol-Gel Process, Jpn. J. Appl. Phys. Part 2, 2000, vol. 39, no 6A, pp. L524-L526. https://doi.org/10.1143/ JJAP.39.L524

[8] P.N. Butenko, D.I. Panov, A.V. Kremleva, D.A. Zakgeim, A.V. Nashchekin, I.G. Smirnova, D.A. Bauman, A.E. Romanov and V.E. Bougrov, Czochralski grown $\left(\mathrm{Al}_{x} \mathrm{Ga}_{1-x}\right)_{2} \mathrm{O}_{3}$ crystals with variable Al content, Mater. Phys. Mech., 2019, vol. 42, no. 6, pp. 802-807/ https://doi.org/ 10.18720/MPM.4262019_12

[9] A. Kuramata, K. Koshi, S. Watanabe, Y. Yamaoka, T. Masui and S. Yamakoshi, High-quality $\mathrm{\beta}-\mathrm{Ga} \mathrm{O}_{3}$ single crystals grown by edge-defined film-fed growth, Jpn. J. Appl. Phys., 2016, vol. 55, art. 1202A2. http://doi.org/10.7567/JJAP.55.1202A2

[10] S. Masuya, K. Sasaki, A. Kuramata, S. Yamakoshi, O. Ueda and M. Kasu, Characterization of crystalline defects in $\mathrm{\beta}-\mathrm{Ga}_{2} \mathrm{O}_{3}$ single crystals grown by edge-defined film-fed growth and halide vapor-phase epitaxy using synchrotron X-ray topography, Jpn. J. Appl. Phys., 2019, vol. 58 055501. https://doi.org/10.7567/1347-4065/ ab0dba

[11] M. Zinkevich and F. Aldinger, Thermodynamic Assessment of the Gallium Oxygen System, J. Amer. Ceramic Soc., 2004, vol. 87, no. 4, pp. 683-91. https://doi.org/10.1111/j.15512916.2004.00683.x

[12] Z. Galazka, R. Uecker, K. Irmscher, M. Albrecht, D. Klimm, M. Pietsch, M. Brützam, R. Bertram, S. Ganschow and R. Fornari, Cryst. Res.Techn., 
2010, vol. 45, no. 12, pp. 1229-1236. https://doi.org/10.1002/crat.201000341

[13] Z. Galazka, R. Uecker, D. Klimm, K. Irmscher, M. Naumann, M. Pietsch, A. Kwasniewski, R. Bertram, S. Ganschow and M. Bickermann, Scaling-Up of Bulk $\beta-G a_{2} \mathrm{O}_{3}$ Single Crystals by the Czochralski Method, ECS J. Solid State Sci. Technol., 2016, vol. 6, no. 7, Q3007, https://doi.org/10.1149/2.0021702jss

[14] V.N. Maslov, V.I. Nikolaev, V.M. Krymov, V.E. Bugrov and A.E. Romanov, Deposition of $\beta-G a_{2} \mathrm{O}_{3}$ layers by sublimation on sapphire substrates of different orientations, Phys. Sol. State, 2015, vol. 57, pp. 1342-1346. https://doi.org/10.1134/S1063783415070215
[15] N. Arıkan, Z. Charifi, H. Baaziz, S. Uğur, H. Ünver and G. Uğur, Electronic structure, phase stability, and vibrational properties of Ir-based intermetallic compound $\operatorname{IrX}(X=A l, S c$, and $G a)$, J. Phys. Chem. Solids, 2015, vol. 77, pp. 126-32. https://doi.org/10.1016/j.jpcs.2014.10.007

[16] M. Baldini, Z. Galazka and G. Wagner, Recent progress in the growth of $\hat{a}-\mathrm{Ga}_{2} \mathrm{O}_{3}$ for power electronics applications, Mater. Sci.Semicond. Proc., 2018, vol. 78, pp. 132-146. https://doi.org/ 10.1016/j.mssp.2017.10.040

[17] Y. Tomm, P. Reiche, D. Klimm and T. Fukuda, Czochralski grown $\mathrm{Ga}_{2} \mathrm{O}_{3}$ crystals, J. Cryst. Growth, 2000, vol. 220, no. 4, pp. 510-514. https://doi.org/10.1016/S0022-0248(00)00851-4 